\title{
Kimya Öğretmenlerinin Yazılı Sınav Sorularının Yenilenmiş Bloom Taksonomisine Göre Analizi ve ÖSYM Soruları İle Karşılaştırılması
}

\section{The Analysis of Chemistry Teachers Exam Questions in Regards to the Revised Bloom's Taxonomy and Their Comparison with ÖSYM Questions}

\author{
Tamer YILDIRIM ${ }^{1}$
}

• Geliş Tarihi: 02.07.2019 • Kabul Tarihi: 04.05.2020 • Çevrimiçi Yayın Tarihi: 04.05.2020

\section{$\ddot{\mathbf{O z}}$}

Bu çalışma, kimya öğretmenlerinin uyguladıkları sınav sorularını Yenilenmiş Bloom Taksonomisi’ne göre analiz ederek soruların ölçtügüü bilişsel düzeyleri üniversite giriş sınavlarında sorulan kimya sorularının bilişsel düzeyi ile karşılaştırmak amacı ile yürütülmüştür. Nitel araştırma desenlerinden doküman analizi yöntemi kullanılmıştır. Çalışmanın verileri, 2018-2019 eğitim-öğretim yılı Artvin merkezinde yer alan 5 farklı lisede görev yapan kimya öğretmenlerinin eğitim-öğretim yılı boyunca hazırladıkları sınav sorularından (toplamda 787) ve son 6 yıl (20142019) boyunca üniversite giriș sınavlarında sorulan kimya sorularından (207) oluşmaktadır. Araştırma sonucunda; kimya öğretmenlerinin yazılı sorularını, bilişsel süreç boyutunda tamamına yakını (\%98) alt düzey bilişsel süreç becerisi gerektiren hatırlama, anlama ve uygulama basamaklarından sorduğu tespit edilmiştir. Bilgi boyutunda ise öğretmenlerin sorularını daha çok kavramlar bilgisi düzeyinde kullandıkları tespit edilmiştir. Üniversite giriş sınavlarında sorulan soruların kimya öğretmenlerinin soruları ile karşılaştırması yapıldığında; üniversite sınav sorularının kavramlar bilgi boyutunda, kimya öğretmenlerinin sorularının ise olgular bilgisi boyutunda yoğunlaştı̆̆ görülmektedir. Üst bilişsel beceri sorusu ise hem kimya öğretmenleri hem de ÖSYM tarafından hiç sorulmamıştır. Bilişsel süreç boyutu açısından kimya öğretmenlerinin yazılılarda ÖSYM sınavlarına göre oransal olarak daha çok hatırlamaya dayalı soruları kullandıkları sonucuna ulaşılmıştır. ÖSYM sınavlarında ise anlama, uygulama ve çözümleme basamaklarına yönelik sorular daha sık kullanılmıştır.

Anahtar sözcükler: Bloom Taksonamisi, ölçme-değerlendirme, kimya, yazılı sınav, ÖSYM

Atıf:

Yıldırım, T. (2020). Kimya öğretmenlerinin yazılı sınav sorularının yenilenmiş bloom taksonomisine göre analizi ve ÖSYM soruları ile karşılaştırılması. Pamukkale Üniversitesi Eğitim Fakültesi Dergisi,50, 449-467. doi: 10.9779/pauefd. 585602

\footnotetext{
1 Dr. Öğretim Üyesi, Çanakkale Onsekiz Mart Üniversitesi, kimyaci08@hotmail.com ORCİ: 0000-0001-86055384
} 


\begin{abstract}
The aim of this study is to analyze the exam questions prepared by chemistry teachers in accordance with the Revised Bloom's Taxonomy and to compare the cognitive levels assessed by the questions of the chemistry teachers in the study with the cognitive levels assessed by university entrance exam questions. The study is conducted using document analysis, which one of the qualitative research methods. The data consist of the exam questions (787 in total) prepared by chemistry teachers working in 5 different high schools in the center of Artvin province during the 2018-2019 educational year and chemistry questions in university entrance examination tests (207) within the course of 6 year period (2014-2019). The findings of the study suggest that in terms of cognitive processes dimension, nearly all of the questions of the chemistry teachers (\%98) are in the lower cognitive process level and the students are asked from remembering, understanding and applying levels. In terms of knowledge dimension, it is found that that chemistry teachers mostly ask questions at the level of conceptual knowledge. When a comparison is made between the questions of university entrance exam questions and the questions asked by the chemistry teachers, we can see that university entrance exam questions mostly concentrate on conceptual knowledge questions whereas the questions of the chemistry teachers mostly concentrate on factual questions. Procedural knowledge questions are found to be at the same level in both groups. Metacognitive ability questions are never asked by both chemistry teachers and by the Student Selection and Placement Center. In regards to the cognitive processes dimension, it can be concluded the chemistry teachers ask more questions based on remembrance in written exams whereas in university entrance examinations, questions in understanding, applying and analysis levels are used more frequently.
\end{abstract}

Keywords: Assessments, Bloom taxonomy, chemistry, examination, ÖSYM

\title{
Cited:
}

Yildirım, T. (2020). The analysis of chemistry teachers' exam questions in regards to the revised bloom's taxonomy and their comparison with ÖSYM questions. Pamukkale Üniversitesi Eğitim Fakültesi Dergisi, 50, 449-467. doi:10.9779/pauefd.585602 


\section{Giriş}

Ölçme-değerlendirme, eğitimin-öğretimin temel öğelerinden biridir. Ölçme, öğrenilmesi hedeflenen kazanımların öğrenci tarafından hangi oranda öğrenildiğinin gözlenerek sonuçların not veya puan olarak ifade edilmesi; değerlendirme ise öğrencilerin öğrenme kalitesinin hangi düzeyde olduğunu belirlemek için ölçme araçlarından elde edilen sonuçlara göre karar verme işidir (Tekin, 2000). Kimya öğretmenlerin en önemli görevlerden biri, öğrencilerinin eğitimdeki performanslarının değerlendirilmesidir. Bunun için yazılı sınavlar, çoktan seçmeli testler, sözlü sınavlar, proje ödevleri ve ders performansları kullanmaktadırlar. Yazılı sınavlar ve çoktan seçmeli testler nicel, sözlü sınavlar ise nitel ölçme aracı olarak kabul edilir (Cohen ve Manion, 1998). Yazılı sınav türü, Türk fen eğitimi alanında en sık kullanılan ölçme değerlendirme araçlarından biridir (Şimşek, 2001). Yazılı sınav ve test fen eğitiminde güçlü bir eğitim aracıdır (Davis, 1993).

Öğretmenlerin hazırlayıp uyguladıkları yazılı sınavlar, öğrencilerin hedeflenen kazanımlara ne derce ulaşabildiklerini tespit etmeye yarayan basit bir ölçme aracıdır. Buna rağmen, öğretmenlerin sınav hazırlama ve uygulama esnasında ölçme-değerlendirme kurallarına yeteri düzeyde riayet etmedikleri bilinmektedir (Balcı ve Tekkaya, 2000). Ayrıca, öğretmenlerin öğretim programında yer alan kazanımlara uygun sınav soruları hazırlamadıkları ve kendi prensiplerine göre hareket ettikleri ifade edilmiştir (Demircioğlu, Ayas, Demircioğlu ve Çavrar, 2002). Uygulanan öğretimin kalitesi ölçülerek eğitimin verimliliği ortaya çıkarılabilir. Öğrencilere kazandırılması düşünülen davranışların hangi oranda öğretildiğini tespit etmek için geçerli ve güvenir ölçme araçları kullanılmalıdır. Öğretmenler farklı bilişsel seviyelerde, konuyu bütün yönleri ile irdeleyen sorular hazırlayarak farklı seviyelerdeki öğrencilerin öğrenmesini sağlayabilmelidirler. (Özmen ve Karamustafaoğlu, 2006). Üst düzey sorular, öğrencilerin daha yaratıcı ve çok boyutlu düşünmelerini sağlayabilir (Brualdi, 1998). Çünkü düşünme becerisinin soru türlerine göre geliştiği bilinmektedir. Yüksek bilişsel seviyesi sorular yöneltilen öğrencilerin, düşük seviyedeki sorularla karşılaşan öğrencilere göre daha yüksek düşünme yeteneğine sahip oldukları görülmüştür. (Brualdi, 1998; Selçuk, 2000). Yazılı sınavlarda kullanılan açı uçlu sorular öğrenciyi düşünmeye sevk eder. Düşünme yeteneğini geliştirmenin bir yolu da açı uçlu sorulardır. Öğrencinin düşünmeye zorlandığ 1 eğitim ortamlarında daha iyi öğrenme gerçekleşebilir. Bu nedenle sorular hazırlanırken öğrencilerin bilişsel düzey alanları dikkate alınmalıdır. Öğrenmenin daha kalıcı olması için öğrenci, düşünmeyi sağlayan sorularla baş başa kalmalıdır (Koray, Altunçekiç ve Yaman, 2002).

Fen derslerinde öğrencilerin daha üst düzey bilişsel düşünme yeteneklerini geliştirmeye çalışılmaktadır (Karamustafaoglu, 2009). Bunu başarmak için, basit uygulamalardan ve düşük seviye kavramlar yerine öğrencilerin bilgiyi karmaşık problemlere uygulama ve sentezleme yetenekleri ön plana çıkarılmalıdır. Yapılandırmacılığa dayanan mevcut görüşe göre, ölçmedeğerlendirmenin öğrencilerin kavramsal bilgileri yeni durumlarda kullanma veya gerçek hayattaki problemleri çözme yetenekleri gibi üst düzey bilişsel becerilerine dokunması beklenir (Zoller ve Pushkin, 2007). Öğrencilerin sadece bilgiyi hatırlama veya rutin algoritmik alıştırmaları çözme yetenekleri gibi düşük dereceli bilişsel becerilerini ölçülmemelidir. Buna rağmen, düşük dereceli bilişsel becerileri ölçen geleneksel tipte sınavlar kimya eğitimi alanında çok sık olarak kullanılmaktadır (Tsaparlis ve Zoller, 2003). Öğretmenler, sınavlarda öğrenciye kazandırmaya çalıştıkları düşünme becerilerini kullanmayı gerektiren sorular sormalıdır. 
Bundan dolayı, yazılı sınavlarda, sorular, üst düzey bilişsel düşünme yeteneklerini geliştirmeye amaçlı olarak iyi hazırlanmalıdır (Colletta ve Chiappetta, 1989).

Öğretimin kalitesini arttırmak için, öğretmenin doğru, geçerli sorular belirleyebilmesi gerekir. Öğrencilerin kavramsal gelişimlerinin yüksek dereceli bilişsel becerilere ulaşıp ulaşmadığının belirlenmesinde ölçme-değerlendirme önemli bir aşamadır. Tüm lise türlerinde kimya öğretimini değerlendirmek için, okul sınavlarında sorulan soruların kalitesini belirlemek önemlidir. Öğrencilerin öğrenme seviyelerinin ne derece hedeflenen kazanımlara uygun olduğunu belirlemek için yazılı sınav sorularının analizinin yapılması gereklidir. Ölçmedeğerlendirme amacıyla geliştirilen soru seviyelerinin belirlenmesinde en sık kullanılan yaklaşım Bloom Taksonomisidir. $\mathrm{Bu}$ Taksonomi, genellikle öğretmenlerin öğrencilerin düşünme becerilerini ölçmek amacıyla sordukları soruların tasarımında kullanılmıştır. $\mathrm{Bu}$ tasarımda bilişsel düzeyler bilgi, kavrama, uygulama, analiz, sentez ve değerlendirme şeklinde ayrılmıştır (Krathwohl, 2002). Tek boyutlu bu tasarım daha sonra geliştirilerek bilgi iki boyutta eş zamanlı incelenmektedir. Yeni yapılandırılmış taksonomide yatay olarak bilgi boyutu, dikey olarak ise bilişsel süreç boyutu bulunmaktadır. Bilgi boyutunda dört kategori vardır. Bunlar olgular bilgisi, kavramlar bilgisi, işlemler bilgisi ve üstbilişsel bilgidir. Bilişsel süreç boyutu kategorisinde ise bilgi boyutu ile kesişecek şekilde hatırlama, anlama, uygulama, çözümleme, değerlendirme ve yaratma basamakları bulunmaktadır. Bu basamakları biraz açacak olursak olgusal bilgi; öğrencilerin bir konuyla ilgili kesinlikle bilmeleri gerekli olan veya problem çözmeye yarayacak temel ögeleri içermektedir. Konuyla ilgili terimler, olgular, kavramlar, simgeler olgusal bilgiye örnek olarak gösterilebilir. Kavramsal bilgi kategorisinde ise, sinıflandırma, kategorizleme, genelleme, kuram ve teoriler gibi daha kapsamlı bilgi, bir yapıyı oluşturan kısımların bir arada hareket etmesini sağlayan ilişkiler bulunmaktadır. İşlemsel bilgi; algoritmalar, yöntem ve teknikler, işlem yolları gerektiren bilgiler gibi uygun metotları kullanma bilgisidir. Üst bilişsel bilgi ise, kendi bilişsel bilgisinin farkında olmayı gerektiren bilgilerdir. Stratejik bilgi, özbilgi bu kapsamda örnek verilebilir (Anderson ve Krathwohl, 2010).

Öğretimin niteliğinin hangi düzeyde olduğunu belirlemek ve öğretmenlerin yaptığ1 sınavların ölçme-değerlendirme açısından ne kadar geçerli ve güvenilir olduğunu tespit etmek için öğretmenlerin yazılı sınavlarında sordukları soruların analiz edilip, soruların niteliklerinin belirlenmesi ve ayrıca farklı örneklem grupları ile veya merkezi sınav soruları ile karşılaştırılması önemli bir konudur. Öğretmenlerin yaptıkları sınavları analiz eden Çepni ve Azar, (1998) en çok bilgi, kavrama ve uygulama basamaklarındaki sorulara yer verildiği, bununla beraber analiz, sentez ve değerlendirme basamaklarında soruların oldukça az yer aldığını belirlemişlerdir. Öğretmenlerin genellikle kullandıkları testlerde yer alan alt düzey soruların öğrencilerin zihinsel yeteneklerini geliştirmediği, onları düşünmeye sevk etmediği bilinmektedir (Çepni, Ayas, Johnson ve Turgut, 1997). Liselerde görev alan öğretmenlerinin etkili soru hazırlayamadıkları, soru hazırlama teknikleri hususunda yetince bilgi sahibi olmadıkları dile getirilmiştir (Çepni ve Azar, 1998). Öğretmenlerin öğretim programında yer alan kazanımlara göre sınav sorusu hazırlama hususuna dikkat etmedikleri ve kendilerine göre farklı ölçütler geliştirip soru hazırladıkları belirtilmiştir (Demircioğlu ve diğerleri, 2002). Literatürde fen ve kimya dersleri yazılı sorularının analiz edildiği çeşitli çalışmalar mevcuttur. Karamustafaoğlu, Sevim, Karamustafaoğlu ve Çepni (2003), farklı illerde yapılan kimya sınavlarında sorulan soruları Bloom taksonomisine göre analiz ederek karşılaştırmışlardır. \% 96 
oranında soruların düşük dereceli bilişsel beceri türünde olduğu ve iller arasında anlamlı bir fark olmadığı tespit edilmiştir. Zorluoğlu, Bağrıyanık ve Şahintürk (2019)'ün yakın tarihte yaptıkları çalışmada ortaokuldan liseye geçiş sınavı olan TEOG'da sorulan fen ve teknoloji sorularını Revize Edilmiş Bloom Taksonomisine göre analiz etmişlerdir. Çalışma sonucuna göre soruların bilişsel süreç ve bilgi boyutu düzeylerinde homojen olarak dağılmadığı, üst bilgi ve üstbilişsel süreç becerilerinin boyutları hakkında yeterli soru sorulmadığı rapor edilmiştir. Güleryüz ve Erdoğan, (2018) tarafından eski Bloom Taksonomisi üzerinden benzer örneklem gruba yapılan çalışmada sonucunda öğretmenlerin hazırladıkları soruların \%59,5'i bilgi, \%20,4'ü kavrama, $\% 13,4$ 'ü uygulama, \%5,2'i analiz, \%1,5'i sentez ve \%0'1 değerlendirme düzeyinde olduğu rapor edilmiştir. Ülkemizin aksine Tıkkanen ve Aksela (2012) Finlandiya kimya sınav sorularını revize edilmiş Bloom Taksonomisi'ne göre analiz etmişlerdir. Soruların çoğunluğunun (\% 77) üst düzey bilişsel beceriler gerektirdiği rapor edilmiştir. Köğce ve Baki (2009) ÖSS sınavı matematik soruları ile liselerde görev alan matematik öğretmenlerinin yazılı sınavlarda sordukları soruları Bloom Taksonomisi'ne göre karşılaştırmışlardır. ÖSS'de sorulan sorular ile genel ve mesleki liselerde de sorulan soruların bilişsel yönden farklılaştığı, ancak Anadolu ve Fen liselerinde sorulan sorular ile bilişsel yönden benzeştiği sonucuna ulaşılmıştır. Karamustafaoğlu, Karamustafaoğlu, Bacanak ve Değirmenci (2010) farklı illerdeki biyoloji öğretmenleri tarafindan sorulan soruları Bloom'un Taksonomisine göre bilişsel alandaki okul türlerini belirleyip ve birbirleri karşılaştırmak amacıyla yürüttükleri çalışmada, soruların düşük dereceli bilişsel beceri tipinde oldukları sonucuna ulaşmışlardır. Üner, Akkuş ve Kormalı (2014) kimya ders kitaplarında ve yazılı sınavlarda geçen soruların bilişsel durumunu Bloom Taksonomisi'ne göre incelemişlerdir. Araştırma sonucunda; ders kitapları ve yazılı sorularında alt düzey bilişsel beceri gerektiren bilgi, kavrama ve uygulama kategorilerinde soruların çok fazla yer aldığı rapor edilmiştir. Kocakaya ve Gönen (2010) fizik dersi açısından benzer bir çalışma yapmışlardır. Soruların \%72,5 oranında düşük bilişsel düzeyde olduğunu bulmuşlardır. Ayvacı ve Türkdoğan (2010) fen bilgisi öğretmenlerinin hazırladıkları yazılı sorularının Yenilenmiş Bloom taksonomisine göre sınıflandırmış ve uygulanan soruların \%55 oranında hatırlama ve bilme kategorisinde olduğunu ifade etmişlerdir. Demircioğlu ve Demircioğlu (2009) kimya öğretmenlerinin sınavlarında kullandıkları soruların, hedeflenen kazanımları ne oranda temsil ettikleri, kaliteleri ve soruları nasıl geliştirdiklerini belirlemek amacı ile çalışma yapmışlardır. Çalışma sonucunda öğretmenlerin ölçme-değerlendirme konusunda yetersiz oldukları ve sorularını hazırlarken hedeflenen kazanımlara dikkat etmedikleri rapor edilmiştir.

Öğretmenler, yaptıkları sınavlar ile öğrencilerin geleceğini etkileyecek kararlar vermekte ve bir üst öğrenime geçişe hazırlamaktadırlar. Ortaöğretimden sonra öğrencilerin yükseköğrenimlerine devam etmeleri için ÖSYM (Öğrenci Seçme ve Yerleştirme Merkezi) tarafindan düzenlenen üniversite giriş sınavlarına girerek başarılı olmaları gerekmektedir. $\mathrm{Bu}$ sınavlardaki soruların bilişsel düzeyleri ile okullarda uygulanan sınavlarda sorulan soruların bilişsel düzeyleri arasında bir benzerlik olması gereklidir. Aksi durumda ortaöğretimi başarı ile bitiren ve yükseköğretime devam etmek isteyen öğrencilerin ÖSYM sınavlarında başarılı olmaları zorlaşacaktır. Bundan dolayı, öğretmenlerin kullandıkları ölçme araçlarının analiz edilerek üniversite giriş sınavlarındaki sorularla karşılaştırılmaları önemlidir. Literatürde yapılan çalışmalar genellikle öğretmenlerin uyguladıkları sınavların Bloom Taksonomisi'ne göre analiz edilerek hangi bilişsel düzeyde olduklarını tespitine yönelik olmuştur. Bu çalışmanın amacı ise Artvin ilinde görev yapan kimya öğretmenlerinin hazırladıkları sınav sorularını 
Yenilenmiş Bloom Taksonomisi'ne göre analiz ederek soruların ölçtüğü bilişsel düzeyleri üniversite giriş sınavlarında sorulan kimya sorularının bilişsel düzeyi ile karşılaştırmaktır. Kimya öğretmenlerinin yaptıkları sınavların üniversite giriş sınavları ile karşılaştırılmasına yönelik daha önce herhangi bir çalışmanın olmaması bu araştırmayı önemli kılmaktadır. Araştırmanın amacı doğrultusunda aşağıdaki sorulara cevap aranmıştır;

- Kimya dersi sınav soruları Yenilenmiş Bloom Taksonomisine göre hangi düzeydedir?

- Üniversite giriş sınavlarında sorulan kimya soruları, Yenilenmiş Bloom Taksonomisine göre hangi düzeydedir?

- Kimya dersi yazılı soruları ile üniversite giriş sınavı kimya soruları arasında ilişki nasildır?

\section{Yöntem}

Araştırma nitel araştırma desenlerinden doküman analizi ile yürütülmüştür. Doküman analizi ile belirli bir zaman diliminde ortaya konulan, olgu ya da olaylar hakkında bilgi içeren yazılı materyallerin incelenmesi ve anlam çıkarmak için analiz edilmesi ile gerçekleştirilmektedir (Yıldırım ve Şimşek, 2011).

\section{Çalışma Grubu}

Çalışma grubunda bulunan 2018-2019 eğitim-öğretim y1lı Artvin merkezinde yer alan 5 okulun (Sosyal Bilimler, Proje İmam Hatip, Endüstri Meslek ve 2 Anadolu lisesi) seçilmesinde kolay ulaşılabilir örnekleme yöntemi tercih edilmiştir. $\mathrm{Bu}$ kurumlarda yazılı sınav sorularını gönüllülük esası ile paylaşan 5 kimya öğretmeninden sınav kâğıtları temin edilmiştir. Üniversite giriş sınavları soruları ise ÖSYM'nin internet sitesinden edinilmiştir.

\section{Veri Toplama Araçları ve Analizi}

Araştırma verileri, 2018-2019 eğitim-öğretim yılı Artvin merkezinde yer alan 5 farklı lisede görev yapan kimya öğretmenlerinin eğitim-öğretim yılı boyunca hazırladıkları sınav sorularından (toplamda 787) ve son 6 yıl (2014-2019) boyunca üniversite giriş sınavları olan YGS, LYS ve YKS sınavlarında sorulan kimya sorularından (207) oluşmaktadır. Veri analiz sürecinde araştırmacı, soruların (öğretmenlerin yazılı soruları ve ÖSYM'nin üniversite giriş sınav soruları) Yenilenmiş Bloom Taksonomi basamaklarına göre sınıflandırmasını yapabilmek için sorularda geçen fiil ifadeleri ve isim ifadelerini belirlemiştir. Daha sonra fiil ifadesinin hangi Bilişsel Süreç Boyutuna yerleştirileceği ve isim ifadesinin hangi Bilgi Boyutuna yerleştirileceğine karar verilerek sorunun Yenilenmiş Bloom Taksonomisindeki yerini belirlemiştir (Anderson ve Krathwohl 2010). Analiz edilen sınav sorularının her birinin Yenilenmiş Bloom Taksonomisinin, bilgi ve bilişsel süreç boyutlarının hangi basamaklarında yer aldığı belirlenirken araştırmanın güvenirliğini artırmak amacıyla ayrıca bir uzman görüşü de alınmıştır. Analizin yapılışı ve Yenilenmiş Bloom Taksonomisi tablosuna (Tablo 1) nasıl yerleştirildiği ile ilgili birkaç örnek aşağıda verilmiştir:

Örnek 1: “ ${ }_{16} \mathrm{~S},{ }_{7} \mathrm{~N}$, $9 \mathrm{~F}$ atomlarının, elektronegatifliklerini karşılaştırınız” sorusundaki “ ${ }_{16} \mathrm{~S}$, ${ }_{7} \mathrm{~N},{ }_{9} \mathrm{~F}$ atomlarının, elektronegatiflikleri” ad ifadesi bilgi boyutunun kavramlar bilgisi kategorisine, "karşılaştırınız" fiil ifadesi ise bilişsel süreç boyutunun karşılaştırma yapma gerektirdiğinden anlama düzeyine karşıllk gelmektedir. 


$\begin{array}{cccc} & \text { Örnek } & \text { 2: } & \text { "Aşağıdaki formülü verilen bileşiklerin adlarını yazınız? } \\ \mathrm{Cl}_{2} \mathrm{O}_{7}: & \mathrm{H}_{2} \mathrm{O}: & \end{array}$

$\mathrm{NH}_{3}: \quad \mathrm{SF}_{6}:$

$\mathrm{Hg}(\mathrm{OH})_{2}$ : $\quad \mathrm{PbO}$ :

$\mathrm{Mg}_{3}(\mathrm{PO} 4)_{2}: \quad \quad \mathrm{Li} 3 \mathrm{P}:$

$\mathrm{K}_{2} \mathrm{SO}_{4}$ : $\quad \mathrm{CH}_{3} \mathrm{COONa:"}$

sorusundaki "formülleri verilen bileşiklerin adları" isim ifadesi terim, sembol bilgisi içerdiğinden olgular bilgisi kategorisine, "yazınız" fiil ifadesi ise formülleri verilen bileşiğin isminin hatırlanmasını gerektirdiğinden bilişsel süreç boyutunda hatırlama kategorisine karşılık gelmektedir.

Örnek 3: "64 $\mathrm{g} \mathrm{O}_{2}$ gazı kaç tane molekül ve kaç mol atom içerir? (O:16)" sorusundaki "64 $\mathrm{g} \mathrm{O}_{2}$ gazı tane molekül ve mol atom" ad ifadesi işlemler becerisi gerektirdiğinden işlemler kategorisine, "kaç tane içerir" fiil ifadesi hesaplama yapma gerektirdiğinden uygulama düzeyine karş1lık gelmektedir.

Örnek 4: “ Asit yağmurları nasıl oluşur? Reaksiyonları ile açıklayarak, etkilerini yazınız" sorusundaki "asit yağmurları" ad ifadesi bilgi yapısının kavranması gerektiğinden kavramlar bilgisi kategorisine, "nasıl oluşur, açıklayınız ve etkilerini yazınız" fiil ifadesi bilişsel süreç açısından hipotez oluşturulup kompozisyon yazma gerektirdiğinden yaratma kategorisine karşı1ık gelmektedir.

Örnek 5: “ $\quad$ Faraday kanunları ile ilgili olarak,

I. 1 mol elektron 1 faradaylık elektrik yük miktarına eşittir.

II. Devreden geçen yük miktarı zamanla ters orantılıdır.

III. Elektrotlarda toplanan maddelerin kütlesi molekül kütleleri ile doğru orantılıdır.

yargılarından hangileri doğrudur? "sorusundaki "Faraday Kanunları" ad ifadesi kavramlar bilgisi kategorisine, "hangileri doğrudur” fiil ifadesi hatırlama düzeyine karşıllk gelmektedir.

Örnek 6: "Viskozite kavramını tanımlayarak, aynı sıcaklıktaki su ve balın viskozitesinin farklı olmasının nedenini açıklayınız" sorusundaki "viskozite kavramı" ad ifadesi kavramlar bilgisi kategorisine, "nedenini açıklayınız" fiil ifadesi olası sebepleri irdeleme gerektirdiğinden çözümleme kategorisine karşılık gelmektedir.

Örnek 7: " $\mathrm{AlCl}_{3}$ bileşiğinin bağ yapısını gösteriniz ve bağ türünü belirtiniz. (Al:13, $\mathrm{Cl}$ : 17)" sorusundaki " $\mathrm{AlCl}_{3}$ bileşiğinin bağ yapısı ve bağ türü” ad ifadesi bilgi boyutu açısından kavramlar bilgisi kategorisine, "gösterme ve belirtme" fiil ifadesi ise bilişsel süreç boyutu açısından uygulama kategorisine karşıl1k gelmektedir.

Örnek 8: "Üzerinde etiketleri kaybolmuş şekilde bulunan 3 farklı kapta; $\mathrm{Ca}, \mathrm{Al}$ ve $\mathrm{Cu}$ metallerinin olduğu bilinmektedir. $\mathrm{HCl}, \mathrm{HNO}_{3}$ ve $\mathrm{NaOH}$ maddelerini kullanarak kapların hangi metallere ait olduğunu nasıl belirlersiniz? Açıklayınız" sorusunda farklı kaplardaki $\mathrm{Ca}, \mathrm{Al}$ ve $\mathrm{Cu}$ metallerinin, $\mathrm{HCl}, \mathrm{HNO}_{3}$ ve $\mathrm{NaOH}$ maddelerini kullanarak tespit edilmesi ve bu tespitin izah edilmesi istendiğinden bilgi boyutu açısından reaksiyon yazma becerisi gerektiğinden işlemler 
bilgisi kategorisine, 3 farklı kaptaki maddeleri 3 farklı madde ile ayrıştırmak için çözümleme ayırt etme bilişsel süreci gerektirir.

Tablo 1. Örnek Soru Analizlerinin Yenilenmiş Bloom Taksonomisi Tablosundaki Yeri

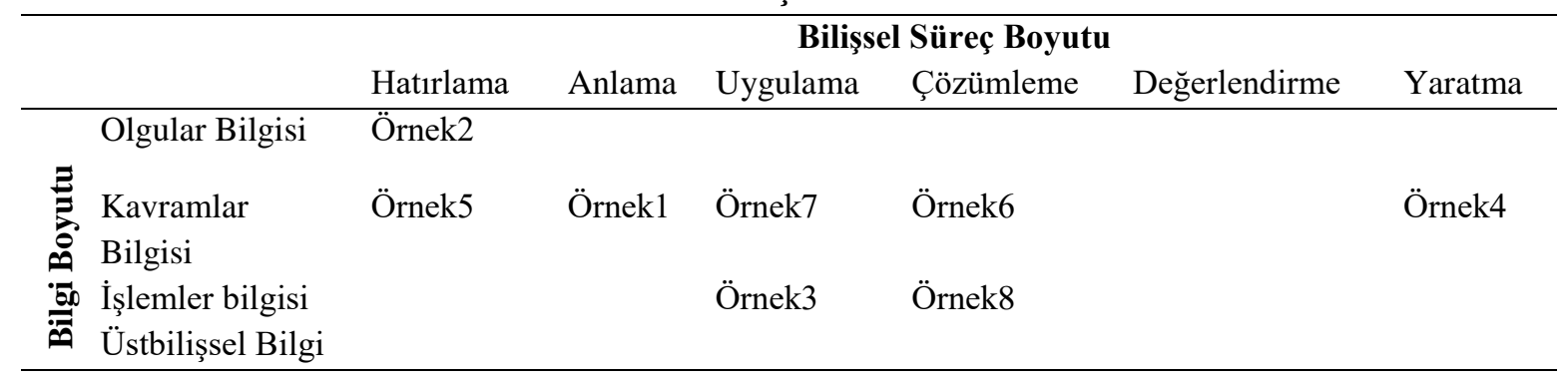

Öğretmenlerin yaptıkları sınav sorularının analiz sonuçları ile üniversite giriş sınav sorularının analiz sonuçları frekans ve yüzde şeklinde ayrı ayrı tablolar halinde sunulmuştur. Daha sonra her iki tablodaki sonuçlar Yenilenmiş Bloom Taksonomisindeki boyutlar açısından grafik sütunu şeklinde ayrıca karşılaştırılmıştır. Yapılan analizlerin güvenilirliğini sağlamak amacı ile araştırmacı bir ay ara ile analizinin ikinci tekrarını yapmıştır. İki analiz arasında \%95 düzeyinde uyum olduğu görülmüştür. Analizin güvenilir olduğu söylenebilir.

\section{Bulgular}

Artvin merkez ilçesinde görev yapan 5 farklı lisede 2018-19 eğitim öğretim yılında uygulanan kimya dersi yazılı sınavlarında sorulan 787 soru Yapılandırılmış Bloom Taksonomisi boyutlarına göre incelenmiş ve frekans ve \% dağılımı Tablo 2'de gösterilmiştir.

Tablo 2. Yazılı Soruların Yenilenmiş Bloom Taksonomisi Tablosuna Göre Dağılımı Bilişsel Süreç Boyutu

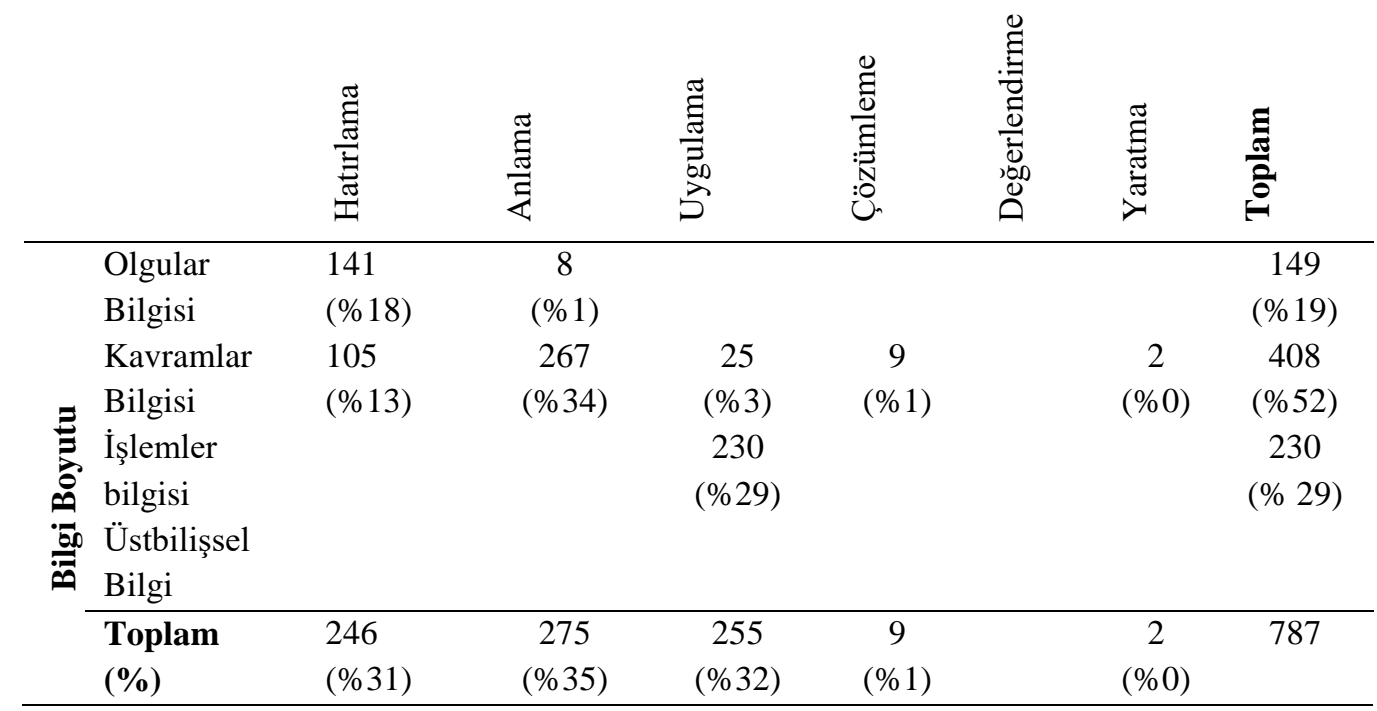

Tablo 2 incelendiğinde bilişsel süreç boyutu açısından en çok anlama düzeyinde (\%35) soru sorulduğu, daha sonra uygulama (\%32) ve hatırlama (\%31) düzeyinde soruların geldiği görülmektedir. Alt düzey bilişsel süreç becerisi gerektiren soruların aksine yüksek düzey bilişsel süreç becerisi gerektiren çözümleme düzeyinde çok nadir soru sorulduğu, değerlendirme ve yaratma düzeyinde ise hemen hemen hiç soru sorulmadığı söylenebilir. Bilgi boyutu açısından 
soruların çoğunluğunun kavramlar düzeyinde (\%52) olduğu bunu işlemler bilgisi (\%29) ve olgular bilgisi (\%19) takip ettiği görülmektedir. Ancak Üstbilişsel bilgi kategorisinde hiçbir sorunun sorulmamış olması dikkat çekicidir. Aşağıda boyutlar açısından bazı örnek sorulara yer verilmiştir.

- " $\mathrm{CO}_{3}{ }^{2-}$ ve $\mathrm{NO}_{3}{ }^{l-}$ iyonlarının toplam elektron saylsı kaçtır? $\left({ }_{6} \mathrm{C},{ }_{8} \mathrm{O},{ }_{7} \mathrm{~N}\right)(8$ puan)". Bilgi boyutu açısından olgusal, bilişsel süreç açısından uygulama düzeylerinde yer alan soru Anadolu İmam Hatip Lisesinde sorulmuştur.

- "BaCl 2 ve $\mathrm{Na}_{2} \mathrm{SO}_{4}$ çözeltileri karıştırılınca oluşacak tepkimenin denklemini yazınız. Net iyon denklemini gösteriniz. ( $\mathrm{BaSO}_{4}$ suda az çözünür) (6P).” Bilgi boyutu açısından olgusal, bilişsel süreç açısından uygulama düzeylerinde yer alan soru Sosyal Bilimler Lisesinde sorulmuştur.

- “ ${ }_{11} \mathrm{Na},{ }_{9} \mathrm{~F},{ }_{19} \mathrm{~K},{ }_{15} \mathrm{P},{ }_{16} \mathrm{~S}$ verilen atomlarinin periyodik cetveldeki yerlerini bulup. atom yarıçaplarını büyükten küçüge sıralayınız (9 puan)." Bilgi boyutu açısından kavramsal, bilişsel süreç açısından anlama düzeylerinde yer alan soru Mesleki Anadolu Lisesinde sorulmuştur.

- " $\mathrm{CO}_{2}$ bileşiğinin bağ yapısını gösteriniz ve bağ türünü belirtiniz $\left.{ }_{6} \mathrm{C},{ }_{8} \mathrm{O}\right)(10 \mathrm{p})$." Bilgi boyutu açısından kavramsal, bilişsel süreç açısından uygulama düzeylerinde yer alan soru Anadolu Lisesinde sorulmuştur.

- “HX'in oda sicaklığında 0,6 M'lık çözeltisinde X iyonları derişimi $6.10-{ }^{5} \mathrm{M}$ dır. Buna göre, aynı sicaklıkta;

a) Asitlik sabiti (Ka) kaçtır? $\quad$ b) HX'in iyonlaşma yüzdesi kaçtır?(8P)." Bilgi boyutu açısından kavramsal, bilişsel süreç açısından uygulama düzeylerinde yer alan soru Mesleki Anadolu Lisesinde sorulmuştur

Son 6 yıl içinde üniversite giriş sınavları olan YGS, LYS ve YKS sınavlarında sorulan 207 kimya sorusu Yapılandırılmış Bloom Taksonomisi boyutlarına göre incelenmiş ve frekans ve \% dağılımı Tablo 3'de gösterilmiştir.

Tablo 3. ÖSYM Sorularının Yenilenmiş Bloom Taksonomisi Tablosuna Göre Dağılımı Bilişsel Süreç Boyutu

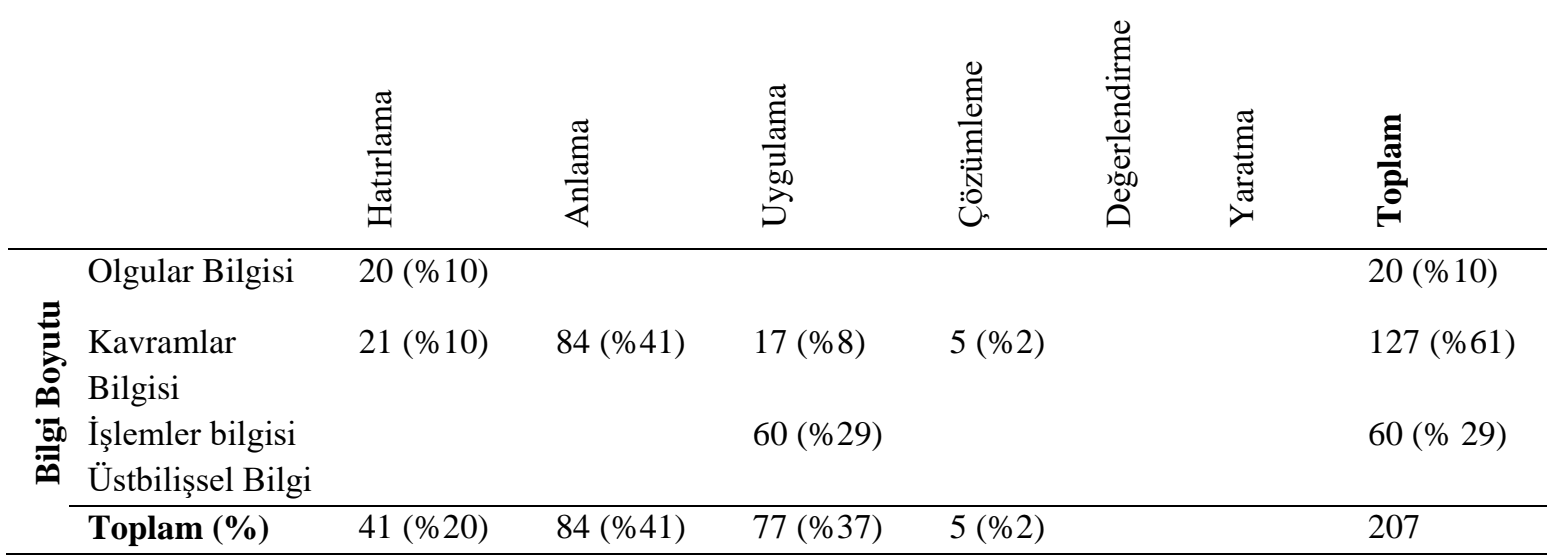

Tablo 3 incelendiğinde bilgi boyutu açısından üniversite giriş sınav sorularının büyük çoğunluğunun kavramlar düzeyinde (\%61) olduğu, daha sonra bunu işlemler bilgisi (\%29) ve 
olgular bilgisi (\%19) düzeylerinde soruların takip ettiği görülmektedir. Üstbilişsel bilgi kategorisinde hiçbir soru bulunmamaktadır. Bilişsel süreç boyutu açısından en çok anlama düzeyinde (\%41) sorunun sorulduğu, daha sonra uygulama (\%37) ve hatırlama (\%20) düzeyinde soruların geldiği görülmektedir. Çözümleme düzeyinde çok nadir soru sorulduğu, değerlendirme ve yaratma düzeyinde ise hiç soru sorulmadığı görülmektedir. Aşağıda boyutlar açısından bazı örnek sorulara yer verilmiştir.

- “Aşağıdaki iyonlardan hangisinin formülü, karşısında yanlış verilmiştir?

Iyon
A) Hipoklorit
$\mathrm{ClO}^{-}$
B) Fosfat
$\mathrm{PO}_{3}^{-3}$
C) Nitrat
$\mathrm{NO}_{3}{ }^{-}$
D) Sülfat
$\mathrm{SO}_{4}^{-2}$
E) Permanganat
$\mathrm{MnO}_{4}{ }^{-“}$

Bilgi boyutu açısından olgusal, bilişsel süreç açısından hatırlama düzeylerinde yer alan 2014 YGS sorusudur.

- "Aşağıda verilen ikili sistemlerin hangisinde moleküller arası hidrojen bă̆ı oluşmaz?
A) Su ve etil alkol
B) Su ve dimetil eter
C) Su ve aseton
D) $S u$ ve karbon tetraklorür
E) Su ve kloroform"

Bilgi boyutu açısından kavramsal, bilişsel süreç açısından çözümleme düzeylerinde yer alan 2015 LYS sorusudur.

- "Kovalent bağlarla ilgili,

I. Yalnızca metal atomları arasında oluşur.

II. Tümü apolar özelliktedir.

III. Elektronların ortaklaşa kullanılmaları sonucu oluşur. yargılarından hangileri doğrudur?
A) Yalnız III
B) I ve II
C)I ve III
D) II ve III
E)I, II ve III"

Bilgi boyutu açısından kavramsal, bilişsel süreç açısından hatırlama düzeylerinde yer alan 2016 YGS sorusudur.

- "Sivıların buhar basıncı ve kaynama sıcaklığıyla ilgili, 
Kimya Öğretmenlerinin Yazıı Sınav Sorularının Yenilenmiş Bloom Taksonomisine Göre Analizi ve ÖSYM Soruları İle Karşılaştırılması

I. Aynı slcaklıkta buhar basıncı büyük olan sıvının kaynama sıcaklı̆̆ı da büyüktür.

II. Ăgzı açık bir kapta sıvının buhar basıncı atmosfer basıncına eşit olduğunda sıvı kaynamaya başlar.

III. Sicaklık arttıkça sıvinın buhar basıncı artar. yargılarından hangileri doğrudur
A) Yalniz I
B)Yalnız II
C) I ve III

D)II ve III

E)I, II ve IIII."

Bilgi boyutu açısından kavramsal, bilişsel süreç açısından anlama düzeylerinde yer alan 2018 YKS sorusudur.

Yenilenmiş Bloom Taksonomisine göre bilgi boyutunda kimya öğretmenlerinin uyguladıkları yazılı sınav soruları ile ÖSYM'nin uyguladığı sınav sorularının karşılaştırılması Şekil 1'de gösterilmiştir.

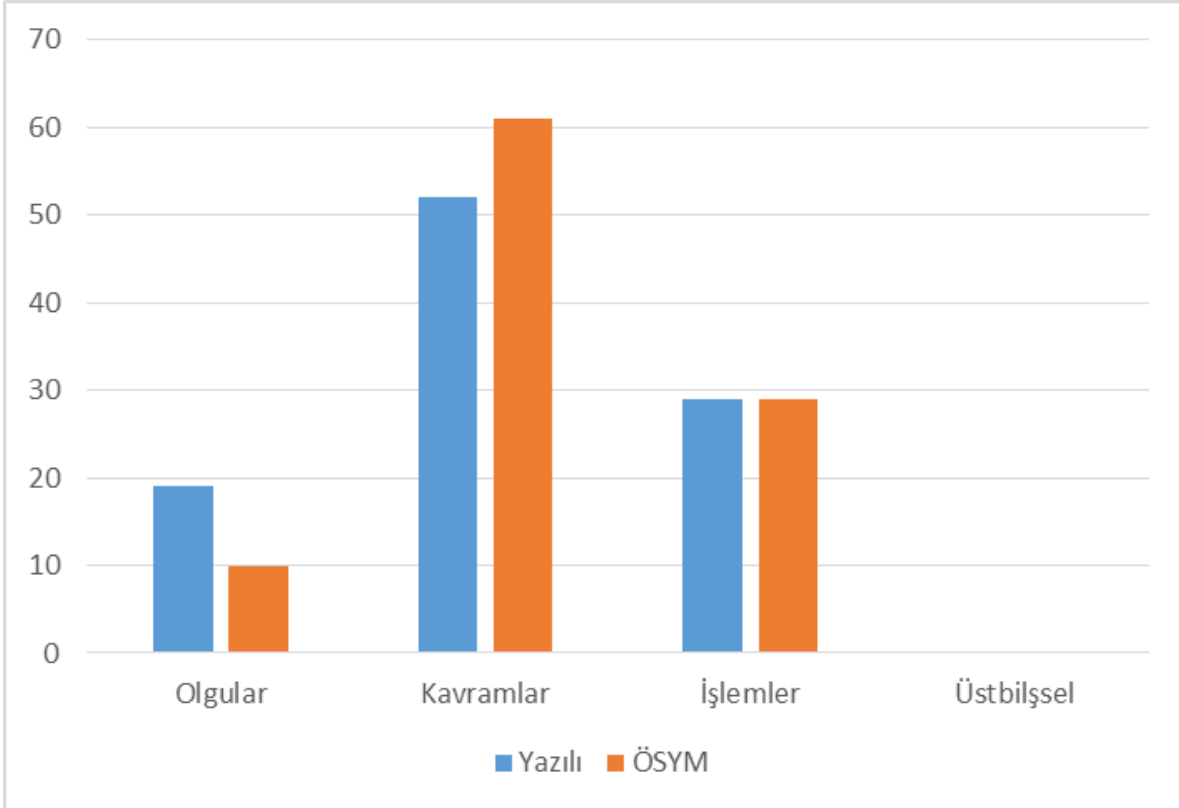

\section{Şekil 1. Yenilenmiş Bloom Taksonomisine Göre Bilgi Boyutunda Sınav Sorularının Karşılaștırılması}

Şekil 1 incelendiğinde bilgi boyutu açısından ÖSYM sınav soruları kavramlar kategorisinde kimya öğretmenlerinin sorularına oranla daha fazla yoğunlaştığı görülmektedir. Kimya öğretmenlerinin sorularında ise olgular boyutu daha çok öne çıkmıştır. İşlemler kategorisinde soruların aynı oranda sorulduğu görülmektedir. Bilişsel süreç boyutunda kimya öğretmenlerinin uyguladıkları yazılı sınav soruları ile ÖSYM'nin uyguladığı sınav sorularının karşılaştırılması ise Şekil 2'de gösterilmiştir. 


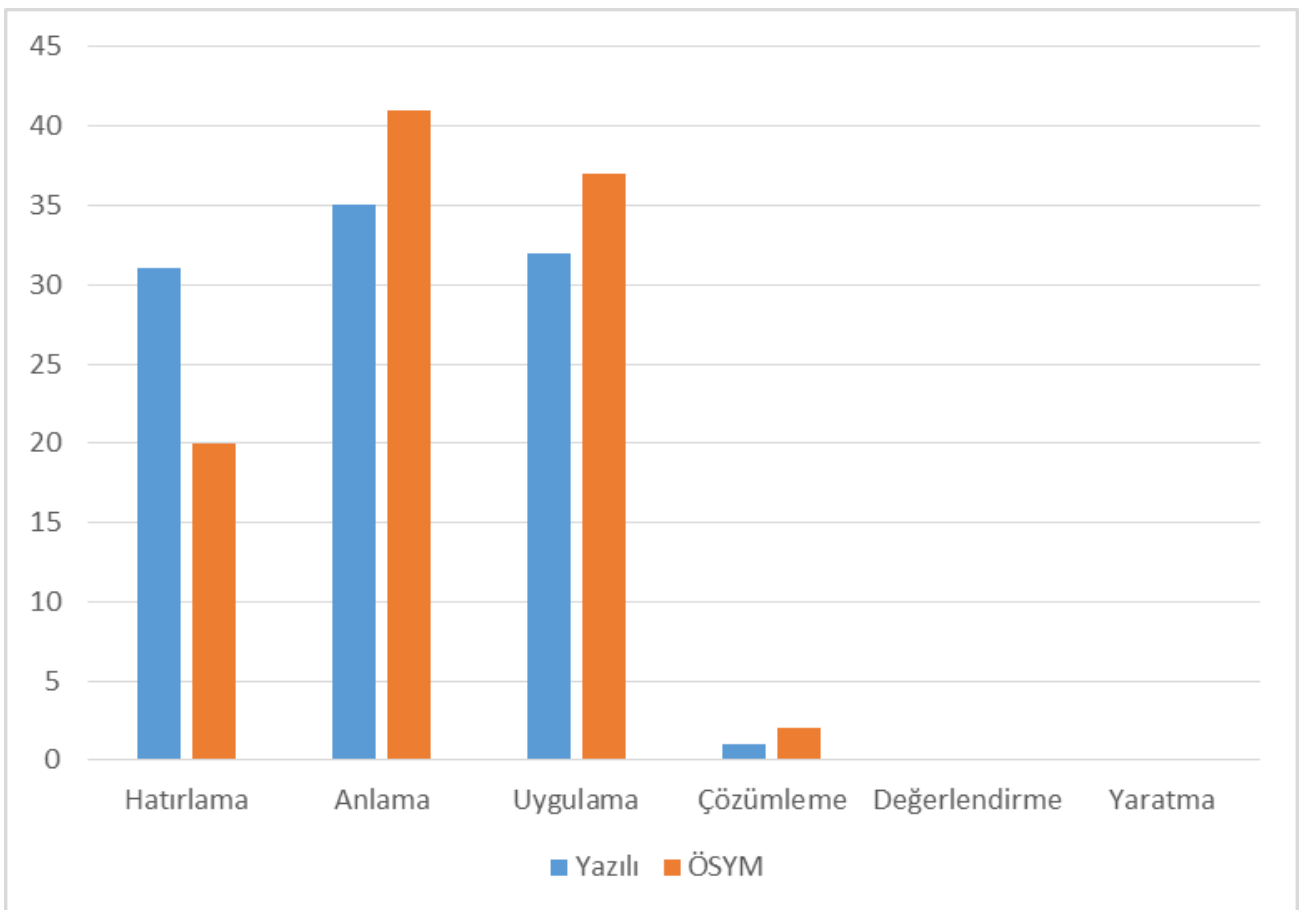

\section{Şekil 2. Yenilenmiş Bloom Taksonomisine Göre Bilişsel Süreç Boyutunda Sınav Sorularının Karşılaştırılması}

Şekil 2 incelendiğinde ÖSYM sınav sorularının kimya öğretmenlerinin uyguladığ 1 yazılı sınav sorularına göre anlama, uygulama ve çözümleme düzeyinde oransal olarak daha çok soru sorarken hatırlama düzeyinde kimya öğretmenlerinin yazılı sınav sorularının daha önde olduğu görülmektedir.

\section{Tartışma ve Sonuç}

Araştırma sonucunda kimya öğretmenlerinin sorularının bilişsel süreç boyutunda tamamına yakını (\%98) alt düzey bilişsel süreç becerisi gerektiren hatırlama, anlama ve uygulama basamaklarından sorulduğu tespit edilmiştir. Öğretmenlerin analiz, değerlendirme ve yaratma gibi üstbilişsel beceri gerektiren sorular sormaktan kaçındıkları ve bilginin anımsanıp uygulanması üzerine sorular sordukları görülmüştür. Ülkemizde yapılan bazı çalışmalarda da aynı şekilde öğretmenlerin yazılı sorularında alt düzey bilişsel beceri gerektiren soruları tercih ettikleri rapor edilmiştir (Güleryüz ve Erdoğan, 2018; Karamustafaoğlu, Sevim, Karamustafaoğlu ve Çepni, 2003; Karamustafaoğlu, Karamustafaoğlu, Bacanak ve Değirmenci, 2010; Şanlı ve Pınar, 2017; Üner, Akkuş ve Kormalı, 2014). Buradan öğretmenlerin Bloom taksonomisinin bilimsel süreç boyutunu dikkat alarak soru hazırlamadıkları görülmektedir. $\mathrm{Bu}$ durum öğrenci seviyesinden kaynaklanabileceği gibi kimya ders programında hedeflenen kazanımların bilişsel süreç basamaklarından da kaynaklanabilir. Nitekim Zorluoğlu, Kızılaslan ve Sözbilir (2016) yaptıkları çalışmada kimya öğretim programı kazanımlarını Yapılandırılmış Bloom Taksonomisine göre analiz etmişler ve sonuçta kazanımların hatırlama, anlama ve uygulama gerektiren alt düzey bilişsel süreç gerektirdiğini rapor etmişlerdir. Finlandiya'da yürütülen benzer bir çalışmada ise kimya öğretmenlerinin sınavlarda büyük oranda analiz, değerlendirme ve yaratma becerisi gerektiren üst düzey bilişsel beceri soruları sorulduğu tespit edilmiştir (T1kkanen ve Aksela, 2012). Ülkemizde de üst düzey bilişsel becerileri artıracak 
programların ve soruların hazırlanması gereklidir. Öğrenciyi düşünmeye sevk edecek ve daha anlamlı öğrenmesini sağlayacak şekilde nicel sorulara "neden", "niçin" gibi kısa sözlü açıklamalar istenerek sorular daha üst bilişsel basamağa dönüştürülebilir. Yine sorulara grafik, tablo ve resimler eklenerek öğrencilerin analiz yapma ve bu bilgileri yeni bilgi üretmede kullanmaları sağlanabilir böylece öğrencilerin üst bilişsel becerileri geliştirilmeye çalış1labilir.

Bilgi boyutu açısından kimya öğretmenlerinin kavramlar bilgisini daha çok kullandıkları sonucuna ulaşılmıştır. Bunun yanı sıra işlemler bilgisi ve olgular bilgisi de kayda değer miktarda sorulmuş ancak üstbilişsel bilgi hiç sorulmamıştır. Kavramsal öğrenmenin önem kazandığı son yıllarda kavramlar bilgisinin ölçülmeye çalışması olumlu bir gelişme olarak görülebilir. Demircioğlu ve Demircioğlu (2009) yaptıkları araştırmada kimya öğretmenlerinin işlemsel beceri gerektiren soruları daha çok tercih ettiğini ve Ayvacı ve Türkdoğan (2010) ise fen öğretmenlerinin yazılılarda olgusal bilgiyi ölçen soruları daha sık kullandıklarını dile getirmişlerdir. Nakhleh'in (1993) öğrencilerin işlemsel beceri gerektiren algoritmik soruları çözmelerine rağmen kavramsal soruları çözmekte zorlandıkları vurgusu dikkate alındığında öğretmenlerin kavramlar bilgisini öne çıkarmaları olumlu bir sonuçtur.

Üniversite giriş sınavlarında sorulan soruların kimya öğretmenlerinin soruları ile karşılaştırması yapıldığında; üniversite sınav sorularının kavramlar bilgi boyutunda, kimya öğretmenlerinin sorularının ise olgular bilgisi boyutunda yoğunlaştığı sonucuna ulaşılmıştır. İşlemler bilgisi soruları iki grupta da aynı seviyede çıkmıştır. Üstbilişsel beceri sorusu ise hem kimya öğretmenleri hem de ÖSYM tarafindan hiç sorulmamıştır. Ortaöğretimin temel hedeflerinden biri de öğrencileri bir üst öğretime hazırlamaktır. Öğrencilerin bir üst öğrenim olan yükseköğretime devam edebilmeleri ÖSYM tarafindan hazırlanan sınavlarda başarılı olmalarına bağlıdır. Bu nedenle kimya öğretmenleri de olgular bilgisi sorularını azaltarak kavramlar bilgisine ölçen sorulara biraz daha ağırlık vermesi gerekmektedir. Zorluoğlu, Kızılaslan ve Sözbilir (2016) yaptıkları çalışmada kimya öğretim programında 154 kazanımdan 7 tanesinin üstbilişsel bilgi içeren kazanım olduğu rapor edilmiş olmasına rağmen ne kimya öğretmenleri ne ÖSYM bu tarzda soru sormuştur. Bunun nedeni test usulü yapılan sınavlarda üstbilişsel bilgini ölçülmesinin zorluğu olabilir ancak kimya öğretmenleri yaptıkları klasik sinavlarda bu tür bilgiyi ölçebilirler. Öğrenciyi düşünmeye ve üretmeye zorlayacak üştbilişsel bilgilerin sınavlarda yer almaması ülkemiz açısından önemli bir sorundur. Milli Eğitim yetkililerin ve araştırmacıların bu konuyu önemsemeleri yararlı olacaktır.

Bilişsel süreç boyutu açısından kimya öğretmenlerinin yazılılarda ÖSYM sınavlarına göre oransal olarak daha çok hatırlamaya dayalı soruları kullandıkları sonucuna ulaşılmıştır. ÖSYM sınavlarında ise anlama, uygulama ve çözümleme basamaklarına yönelik sorular daha sık kullanılmıştır. Fen derslerinde akademik başarıları yüksek olan öğrencilerin ÖSYM sınavlarında birçok soru ile başa çıkamadıkları bilinmektedir (Morgil ve Bayan, 1996). Öğretmenlerin öğrencilerinin üniversite sınavlarında başarılı olmaları için yazılı soru düzeylerinde iyileştirme yapmaları, hazırlaması kolay olan hatırlamaya dayalı sorular yerine açıklamaya, yorumlamaya ve analiz yapmaya dayalı soruları hazırlamaları faydalı olacaktır. Türkiye'de, öğrencilerin yaşamında bir dönüm noktası olan ÖSYM sınavlarında sorulan soruların çoğu, analitik düşünme ve kavramların çapraz incelenmesini gerektirir (Tezbaşaran, 1994). Köğce ve Baki (2009)'nin Matematik dersi için ve Kocakaya ve Gönen (2010)'in Fizik dersi için yaptıkları üniversite giriş 
sınav soruları ile öğretmenlerin sınav sorularını karşılaştırmaya yönelik çalışmalarda da benzer sonuçlar bulunmuştur.

Hem ÖSYM sınavlarında hem de kimya öğretmenlerin yazılı sınavlarında değerlendirme ve yaratma basamaklarında soru sorulmamış olması dikkat çekicidir. Benzer sonuç ortaokul Fen ve Teknoloji dersi için yapılan çalışmada da rapor edilmiştir (Zorluoğlu, Bağrıyanık ve Şahintürk, 2019). Öğrencilerin eleştirel düşünme yeteneklerinin gelişmesi ve bilgi üretebilmeleri günümüzün önemli eğitim-öğretim meselelerindendir. Yüksek bilişsel düzeydeki değerlendirme ve yaratma soruları öğrencileri sorgulamaya ve üst düzey düşünmeye yönlendirir. Öğrencilerin daha fazla zihinsel yetenekleri gerektiren üst düzey bilişsel becerileri kullanabildikleri vakit daha fazla bilgiyi anımsayabildikleri ve bu bilgileri daha etkili kullanabildikleri bilinmektedir (Hotiu 2006). Daha kalıcı öğrenmenin gerçekleşmesi için tanıma ve anımsamaya yönelik sorulardan ziyade analiz yapma, irdeleme, eleştirme ve üretme gerektiren bilişsel süreçle ilgili sorulara daha fazla yer verilmelidir.

Araştırmanın sonuçları 1şığında şu önerilerde bulunulmuştur:

- Farklı örneklem grupları ile öğretmenlerle mülakat yapılarak onların çeşitli ölçme araçları ile ilgili yaklaşımları ve uygulamalarına yönelik daha ayrıntılı veriler toplanacağı araştırmalar yapılabilir.

- Öğretmenler yaptıkları sinavlarda öğrencilerin eleştirel düşünce becerilerini geliştirmeleri ve yeni bilgiler yapılandırabilmeleri için üst düzey bilişsel basamakları dikkate alarak sınav sorularını hazırlamalıdır.

- Öğretmenler ölçme-değerlendirmede kullanılan sınıflandırma türlerini, Taksonomi Basamaklarını nasıl kullanacakları ve soru sorma teknikleri konusunda hizmet içi eğitime alınmalıdır.

- Kimya öğretmenleri ve ÖSYM yetkilileri mümkün olduğunca algoritmik işlem gerektiren sorulardan kaçınarak öğrenciyi düşünmeye zorlayacak kavramsal sorulara yönelmelidir.

- Uzmanlar ve akademisyenlerin işbirliğinde, Bloom taksonomisine uygun sorular hazırlanarak, MEB'nın eğitim portallarında öğretmenlerin yararlanması sağlanabilir.

- Eğitim fakültelerinde öğretmen adaylarına soru hazırlanma hakkında uygulamalı olarak eğitim verilmelidir.

- Öğretim programları hazırlanırken üst bilişsel beceriye yönelik kazanım sayıları artırılmalidır. 


\section{Kaynakça}

Anderson L.W. \& Krathwohl D. R. (2010). Öğrenme öğretim ve dĕgerlendirme ile ilgili bir sınıflama. Çev. D. A. Özçelik. Ankara: Pegem akademi.

Ayvacı, H. Ş., ve Türkdoğan, A. (2010). Yeniden yapılandırılan Bloom taksonomisine göre fen ve teknoloji dersi yazılı sorularının incelenmesi. Türk Fen Eğitimi Dergisi, 7(1), 13-25.

Balcı, E. ve Tekkaya, E. (2000). Ölçme ve değerlendirme tekniklerine yönelik bir ölçeğin geliştirilmesi. Hacettepe Üniversitesi Ĕ̆itim Fakültesi Dergisi, 18, 42-50.

Brualdi, A.C. (1998). Classroom questions, practical assessment. Research \& Evaluation, 6, Eric Documentre production no: ED 422407

Cohen, L. \& Manion, L. (1998). Research methods in education (4th edn.). London: Routledge.

Colletta, A.T. \& Chiappetta, E.L. (1989). Science introduction in the middle and secondary schools (2nd edn.). Ohio, USA: Merrill Publishing Company.

Çepni, S., ve Azar, A. (1998). Lise fizik sınavlarında sorulan soruların analizi. III. Ulusal Fen Bilimleri Eğitimi Sempozyumu. Karadeniz Teknik Üniversitesi Trabzon, 109-114.

Çepni, S., Ayas, A., Johnson, D., \& Turgut, M. F. (1997). Fizik ögretimi. Ankara: YÖK/Dünya Bankası Milli Eğitimi Geliştirme Projesi, Hizmet Öncesi Öğretmen Eğitimi.

Davis BG. (1993). Tools for teaching. Jossey-Bass, Publishers, San Francisco.

Demircioğlu, G., ve Demircioğlu, H. (2009). Kimya öğretmenlerinin sinavlarda sordukları soruların hedef davranışlar açısından değerlendirilmesi. Necatibey Eğitim Fakültesi Elektronik Fen ve Matematik Ĕ̆itimi Dergisi, 3(1), 80-98.

Demircioğlu, G., Ayas, A., Demircioğlu, H. ve Cavrar, S. (2002). Öğrencilerin kimya başarılarını belirlemede kullanılan araçların ve soruların nitelikleri, 2000' li Yıllarda I. Öğrenme ve Öğretme Sempozyumu, Marmara Üniversitesi, İstanbul.

Güleryüz, H. ve Erdoğan, İ. (2018). Orta okul fen bilimleri dersi sınav sorularının bloom'un bilişsel alan taksonomisine göre değerlendirilmesi: Muş ili örneği. Anemon Muş Alparslan Üniversitesi Sosyal Bilimler Dergisi, 6(1), 43-49.

Hotiu, A. (2006). The relationship between item difficulty and discrimination indices in multiple-choice tests in a physical science course. Unpublished master thesis, Florida Atlantic University, Boca Raton, Florida.

Karamustafaoğlu, O. (2009). Fen ve teknoloji eğitiminde temel yönelimler. Kastamonu Eğitim Dergisi, 17(1), 87-102.

Karamustafaoğlu, S., Bacanak, A., Karamustafaoğlu, O., ve Değirmenci, S. (2010). Ses kavramına yönelik bir çoklu zekâ etkinliği. Batı Anadolu Eğitim Bilimleri Dergisi, 1(2), 125-139.

Karamustafaoĝlu, S., Sevim, S., Karamustafaoĝlu, O. \& Çepni, S. (2003). Analysis of Turkish highschool chemistry examination questions according to Bloom's taxonomy. Chemistry Education Research and Practice, 4(1), 25-30.

Kocakaya, S., \& Gönen, S. (2010, June). Analysis of Turkish high-school physics-examination questions according to Bloom's taxonomy. In Asia-Pacific Forum on Science Learning and Teaching, 11(1), 1-14.

Koray, Ö., Altunçekiç, A. ve Yaman, S. (2002). Fen bilgisi öğretmen adaylarının soru sorma becerilerinin bloom taksonomisine göre değerlendirmesi. Pamukkale Eğitim Fakültesi Dergisi, 17(17), 33-39. 
Köğce, D., \& Baki, A. (2009). Matematik öğretmenlerinin yazılı sınav soruları ile ÖSS sınavlarında sorulan matematik sorularının Bloom taksonomisine göre karşılaştırılması. Pamukkale Üniversitesi Ĕ̆itim Fakültesi Dergisi, 26(26), 70-80.

Krathwohl D. R. (2002). A Revision of Bloom's Taxonomy: An Overview. Theory into Practice 41(4), 212-218.

Morgil, F. İ., ve Bayan, S. (1996). Success of secondary school students in solving physics questions of OSS and OYS examinations. Hacettepe Journal of Education, 12, 215-220.

Nakhleh, M.B. (1993). Are our students conceptual thinkers or algorithmic problem solvers? Journal of Chemical Education, 70, 52-55.

Özmen, H. ve Karamustafaoğlu, O. (2006). Lise ii. sınıf fizik-kimya sınav sorularının ve oğrencilerin enerji konusundaki başarılarının bilişsel gelişim seviyelerine gore analizi. Kastamonu Eğitim Dergisi, 14(1), 91-100.

Selçuk, Z. (2000). Okul deneyimi ve uygulama, Nobel Yayıncıllk, Ankara.

Şanlı, C., \& Pınar, A. (2017). Sosyal bilgiler dersi sınav sorularının yenilenen Bloom taksonomisine göre incelenmesi. Elementary Education Online, 16(3), 949-959.

Şimşek, S. (2001). Fen bilimlerinde değerlendirmenin önemi, Milli Eğitim Dergisi, Sayı 148, 30-32.

Tekin, H. (2000). Eğitimde ölçme ve değerlendirme (14. Baskı). Ankara: Yargı Kitap ve Yayınevi.

Tezbaşaran, A. A. (1994). ÖSYS testlerinde yoklanmak istenen bilişsel davranışlar. Hacettepe Üniversitesi Ĕgitim Fakültesi Dergisi, 10, 79-84.

Tikkanen, G., \& Aksela, M. (2012). Analysis of Finnish chemistry matriculation examination questions according to cognitive complexity. Nordic Studies in Science Education, 8(3), 257-268.

Tsaparlis, G., \& Zoller, U. (2003). Evaluation of higher vs. lower-order cognitive skills-type examinations in chemistry: implications for university in-class assessment and examinations. University Chemistry Education, 7(2), 50-57.

Üner, S., Akkuş, H. ve Kormalı, F. (2014). Ortaöğretim kimya ders kitaplarındaki ve sınavlarındaki soruların bilişsel düzeyi ve öğrencilerin bilişsel düzeyiyle ilişsisi. Ahi Evran Üniversitesi Kirşehir Eğitim Fakültesi Dergisi, 15(1), 137-154.

Yıldırım A. \& Şimşek H. (2011). Sosyal bilimlerde nitel araştırma yöntemleri (8.bask1). Ankara: Seçkin Yayıncillk.

Zoller, U. \& Pushkin, D. (2007). Matching higher-order cognitive skills (HOCS) promotion goals with problem-based laboratory practice in a freshman organic chemistry course. Chemistry Education Research and Practice, 8(2), 153-171.

Zorluoglu, S. L., Bagriyanik, K. E., \& Sahintürk, A. (2019). Analyze of the Science and Technology Course TEOG Questions Based on the Revised Bloom Taxonomy and Their Relation between the Learning Outcomes of the Curriculum. International Journal of Progressive Education, 15(2), 104-117.

Zorluoğlu L., Kızılaslan A. \& Sözbilir M. (2016). Ortaöğretim kimya dersi öğretim programı kazanımlarının yapılandırılmış bloom taksonomisine göre analizi ve değerlendirilmesi. Necatibey Eğitim Fakültesi Elektronik Fen ve Matematik Eğitimi Dergisi 10(1), 260-279. 


\section{Extended Abstract}

\section{Introduction}

One of the most important duties of chemistry teachers is the assessments of their students' performances. With this aim, written exams, multiple-choice tests, verbal tests, projects and lecture performances are used. Written and multiple-choice tests are considered quantitative assessment instruments and verbal tests are considered qualitative assessment tools (Cohen and Manion, 1998). Written exam type is one of the most commonly used assessment and evaluation instruments in Turkish science education (Şimşek, 2001). In order to determine whether the conceptual development of the students reach high level cognitive skills or not, assessment and evaluation is an important step. In order to test the levels of cognitive development processes and learning levels of students, we should make an analysis of the questions asked by teachers in exams. The most commonly used approach in the classification of evaluation and assessment levels of questions is the Bloom's Taxonomy. The newly structured taxonomy consists of knowledge dimension and cognitive process dimension. While knowledge dimension consists of factual, conceptual, procedural and metacognitive knowledge levels, the cognitive processes dimension consists of remembrance, understanding, application, analysis, evaluation and creation levels.

Teachers make decisions which greatly influence the future of their students through the exams they administer and prepare them for their transition to a higher level of education. In order to proceed from high-school education to higher education, students need to take the university entrance examination organized by the Student Selection and Placement Center. It can be argued that the cognitive levels of the questions in the exams administered at highschools should be similar to the cognitive levels of the questions in the university entrance examinations. The studies made in literature generally try to inquire on which cognitive levels the exams prepared by teachers at schools are by analyzing them according to Bloom's Taxonomy. The aim of this study is to analyze the exam questions prepared by chemistry teachers working in Artvin province according to the Revised Bloom's Taxonomy and compare the cognitive levels assessed by the teachers' questions with the cognitive levels of the questions in the university entrance examinations. In line with the aim of this study, answers to the questions below are sought;

- On which level are the chemistry teachers' questions with respect to the Revised Bloom's Taxonomy?

- On which level are the chemistry questions in university entrance exams in regards to the Revised Bloom's Taxonomy?

- What is the relationship between chemistry teachers' written questions and university entrance examination questions?

\section{Method}

The study is conducted using document analysis, which is one of the qualitative research methods. The data consist of the exam questions prepared by chemistry teachers (787 in total) working in 5 different high schools in the center of Artvin in the 2018-2019 educational year 
and chemistry questions in the university entrance exams (207 in total) within the course of 6 years (2014-2019).

In the analysis process, the researcher determined the verb and noun expressions for the classification of the questions in accordance with the Revised Bloom's Taxonomy levels. Afterwards, the researcher identified which verb expression is placed to which cognitive process domain and which noun expression is placed to which knowledge domain to determine the place of the question in the Revised Bloom's Taxonomy (Anderson and Krathwohl 2001). An example about how the analysis is made and how it is placed to the Revised Bloom's Taxonomy chart is given below:

Example 1: The noun expression of the electronegativities of ${ }_{16} \mathrm{~S},{ }_{7} \mathrm{~N},{ }_{9} \mathrm{~F}$ atoms in the question "Compare the electronegativities of ${ }_{16} \mathrm{~S},{ }_{7} \mathrm{~N}$, $9 \mathrm{~F}$ atoms" corresponds to the conceptual knowledge of knowledge dimension and "compare" verb expression corresponds to the cognitive process dimension's understanding level. In order to increase the reliability of the study, while determining which levels the knowledge and cognitive process dimensions are located in the Revised Bloom's Taxonomy, expert opinions were taken for each one of the exam questions analyzed. The analyses made are presented in the forms of frequency, percentage and graph charts.

\section{Results}

In conclusion, the findings of the study suggest that nearly all of the questions of the chemistry teachers in the cognitive process dimension (\%98) are asked from remembering, understanding and applying levels, which require basic level cognitive process abilities. It can be argued that teachers avoid asking questions requiring higher order thinking abilities like analysis, evaluation and creation and they ask questions based on the remembrance and the application of the information. As for knowledge dimension, it is determined that chemistry teachers use conceptual knowledge frequently. Moreover, procedural knowledge and factual knowledge are asked extensively but metacognitive knowledge is never asked.

When a comparison is made between the questions of university entrance exams and the questions asked by chemistry teachers, it can be argued that conceptual knowledge is more prominent in questions in university entrance exams and factual knowledge is more prominent in the questions of chemistry teachers. Procedural knowledge questions are found to be at the same level in both groups. Metacognitive ability questions are never asked by both the chemistry teachers and by the Student Selection and Placement Center. In regards to the cognitive process dimension, it can be concluded that chemistry teachers ask more questions based on remembrance in written exams than in university entrance examinations. On the other hand, in regards to the questions in university entrance examinations, the levels of understanding, applying and analysis are more frequently used.

\section{Discussion}

The results of the study reveals that teachers do not prepare their questions by paying attention to the levels of Bloom's Taxonomy. It is possible that this might stem from the levels of students, however; it might also be a result of the cognitive process levels of learning outcomes 
in the chemistry course curriculum. Recently, conceptual learning has been gaining importance and the assessment of conceptual knowledge can be seen as a positive development.

One of the main goals of high-school education is to prepare the students to higher education. The proceeding of students to higher education depends on their success in university entrance examinations. Therefore, chemistry teachers need to lower the number of factual knowledge questions and increase the number of questions assessing conceptual knowledge. Asking metacognitive knowledge questions, which will force the students to think and create in exams, is of great importance for our country and this issue should be taken into consideration by researchers and the authorities at the Ministry of National Education. In order to realize a more permanent learning, questions requiring analysis, examination, criticism and creation should be asked more frequently than questions intended to assess recognition and remembrance. 